\title{
Effect of Menopause on Periodontium - Is There A Link?
}

\author{
Dr. Ruzuta Khushal Bhai Dabhi, ${ }^{1}$ Dr. Aditi Mathur, ${ }^{1}$ Dr. Neema Shetty, ${ }^{1}$ \\ Dr. Barkha Makhijani, ${ }^{1}$ Dr. Balaji Manohar, ${ }^{1}$ Dr. Ashish Bali ${ }^{1}$ \\ ${ }^{1}$ Department of Periodontics, Pacific Dental College, Udaipur, Rajasthan, India.
}

\begin{abstract}
Introduction: Menopause is associated with important systemic and oral changes. Many researchers have tried to evaluate the influence of hormonal changes associated with menopause in the periodontium, however results are still contradictory.

Objective: The aim of the present study was to evaluate the effect of menopause on the severity of periodontal destruction.

Methods: In the present study 25 systemically healthy women age ranges from 30 to 65 with generalised chronic periodontitis were included. They were divided into 2 groups based on their menstrual history. Group I (control group) included 8 women with normal menstrual cycle and Group II (test group) included 17 postmenopausal women. Clinical parameters Plaque Index, Gingival Index, periodontal probing pocket depth (PPD) and DMFT Index was recorded. The level of bone present was evaluated radiographically.

Results: There were no significant differences between subjects of both the control and test groups in the percentages of sites for presence of plaque $(\mathrm{p}>0.37)$, gingival index $(\mathrm{p}>0.161)$ and DMFT index $(\mathrm{p}>0.099)$. However deeper pockets $(\mathrm{p}<0.001)$ and reduced bone support $(\mathrm{p}<0.00)$ was observed in Group II as compared to Group I.

Conclusion: The findings of the present study suggest, that postmenopausal women have more severe periodontal destruction as compared to premenopausal women.

Keywords: Grid; menopause; menstruation; periodontitis.
\end{abstract}

\section{INTRODUCTION}

Throughout a woman's life cycle, hormonal influences affect therapeutic decision making in periodontics. Therefore it is imperative that the clinician recognise, customise, and appropriately alter periodontal therapy according to the individual woman needs based on the stage of her life cycle. ${ }^{1}$ Hormones are specific regulatory molecules that modulate reproduction, growth and development, maintenance of the internal environment, as well as energy production, utilization, and storage. ${ }^{2}$

In woman goes through mainly four stages in her life cycle where hormonal imbalance found are: Puberty, Menstrual cycle, Pregnancy, and Menopause. As women approach menopause, the levels of estrogen begin to drop mainly during the late follicular and luteal phase of the menstrual cycle.

\footnotetext{
Correspondence:

Dr. Ruzuta Khushal Bhai Dabhi

Department of Periodontics, Pacific Dental College, Udaipur, Rajasthan, India.

email: ruzutadabhi2016@gmail.com

Citation

Dabhi RKB, Mathur A, Shetty N, Makhijani B, Manohar B, Bali A. Effect of Menopause on Periodontium - Is There A Link?. J Nepal Soc Perio Oral Implantol. 2019;3(5):13-7.
}

The time frame between regular cycles and the cessation of menstrual periods, called perimenopausal transition, is 2-7 years. ${ }^{3}$ During this period, the concentration of circulating estrogen decreases while follicle stimulating hormone (FSH) and luteinizing hormone (LH) concentrations increase. ${ }^{3}$

Menopause period is increasing and is associated with important systemic and oral manifestations. ${ }^{4,5}$ During menopause, gingival epithelium becomes thinner, atrophic and more prone to inflammatory changes 6 on the other hand, salivary flow rate decreases and salivary composition may be altered, contributing to the development of several oral conditions. ${ }^{7}$

The sudden decrease in estrogen production that occurs in menopause is considered to be the main cause of primary osteoporosis, which also affects jawbones. ${ }^{89}$ It has been suggested that this reduction in bone mineral density could contribute to periodontal disease progression. ${ }^{10}$ Besides their effect on bone, estrogens also interfere with other periodontal tissues (gingiva and periodontal ligament) and influence host immune-inflammatory responses. ${ }^{11-13}$ Osteoporosis is defined by the World Health Organization (WHO) as a "Bone mineral density (BMD) that is 2.5 standard deviations or more below the average value for young healthy women (a T- score of $<$ 2.5 SD)." ${ }^{14}$ Osteoporosis leads to: Poor wound healing - less 
attachment formation; Reduced bone mineral content in the jaws; and Increase of periodontitis and tooth loss. ${ }^{15-17}$

So, the aim of the present study was to evaluate the effect of menopause on periodontal destruction.

\section{METHODS}

Thirty to 65 years old females who reported to Outpatient Department of Periodontology, Pacific Dental College and Hospital, Debari, Udaipur, Rajasthan were enrolled in the study. Detailed medical, dental and menstrual history were recorded and systemically healthy women were enrolled in the study. Informed written consent was taken from each of the patients. It was case control study.

Inclusion criteria:

- Women age ranging from 30 - 65 years.

- Women who are systemically healthy.

- Subjects who diagnosed with chronic generalised periodontitis.

Exclusion Criteria

- $\quad$ Smokers

- Patient on/previous history of hormonal replacement therapy (HRT)

- Patients who have undergone surgical removal of ovary

- Women on contraceptives

- $\quad$ Any abnormality in menstrual cycle

For Subjects sampling, detailed menstrual history was taken and according to their menstrual history they were divided in to two groups:

Group I (Control group) - 8 females with ongoing menstruation.

Group II (Test group) - 17 females with menopause

Periodontal status was checked by measuring the auxiliary parameters like plaque index (Turesky Gilmore Glickman modification of Quigley Hein), ${ }^{18}$ gingival index (Loe and Silness), ${ }^{19}$ DMFT index (Klein, Palmer and Knutson) was measured using the mouth mirror and explorer. ${ }^{20}$ Clinical parameter like probing pocket depth (PPD) was also measured using periodontal probe.

Radiographic assement: Radiograph were taken using the grid and paralleling technique in lower left and right molar region and upper anterior region.

Then marking on grid were measured using the periodontal probe.

Comparison of the clinical and radiographic parameters were done between the Group I and Group II.

Data were entered into a Microsoft Office Excel 2013 ${ }^{\circledR}$ (Microsoft, Seattle, USA) database. The Statistical Package for Social Sciences 17 (SPSS, Chicago, USA) was used for the statistical analysis Student's unpaired t test was performed for intergroup comparison.

\section{RESULTS}

After taking a detailed medical, dental and menstrual history. Patients were divided in two groups according to their menstrual history:

Group I(Control group) - 8 females with ongoing menstruation. Group II (Test group) - 17 females with menopause

The mean value of plaque index was $3.45 \pm 0.97$ and 3.88 \pm 1.18 for Group I and Group II respectively. Statistically non-significant difference was observed when PI of both the groups were compared. ( $p$ > 0.376).Table I, Graph 1

On comparison of gingival index score mean value were 1.45 \pm 0.79 and $1.85 \pm 0.56$ respectively for Group I and Group II which shows nonsignificant difference. $(\mathrm{p}>0.161)$ Table 1 , Graph 2.

For DMFT mean value $1 \pm 1.41$ and $2.41 \pm 2.09$ for Group I and

Table 1: Comparison of PI, GI, DMFT index, PPD and bone loss between Group I and Group II

\begin{tabular}{|l|c|c|c|}
\hline & Group I & Group II & P value \\
\hline PI & $3.45 \pm 0.97$ & $3.88 \pm 1.18$ & 0.376 \\
\hline GI & $1.45 \pm 0.79$ & $1.85 \pm 0.56$ & 0.161 \\
\hline DMFT Index & $1 \pm 1.41$ & $2.41 \pm 2.09$ & 0.099 \\
\hline PPD $(\mathrm{mm})$ & $1.88 \pm 2.59$ & $5.94 \pm 2.56$ & 0.001 \\
\hline Bone Loss $(\mathrm{mm})$ & $0.38 \pm 1.13$ & $2.69 \pm 1.95$ & 0.000 \\
\hline
\end{tabular}

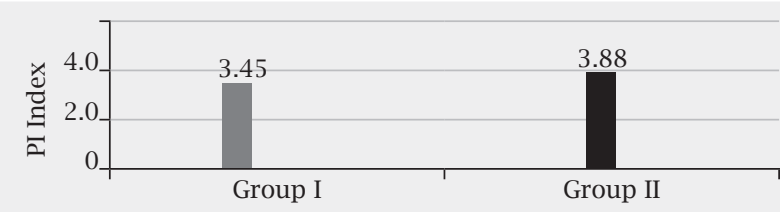

Graph 1: Comparison of PI between Group I and Group II

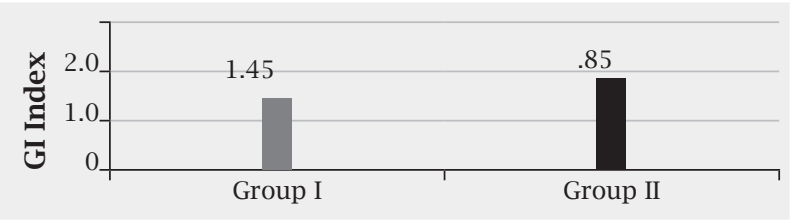

Graph 2: Comparison of GI between Group I and Group II 


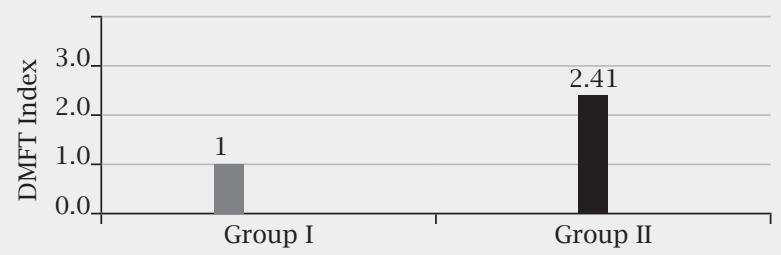

Graph 3: Comparison of DMFT between Group I and Group II

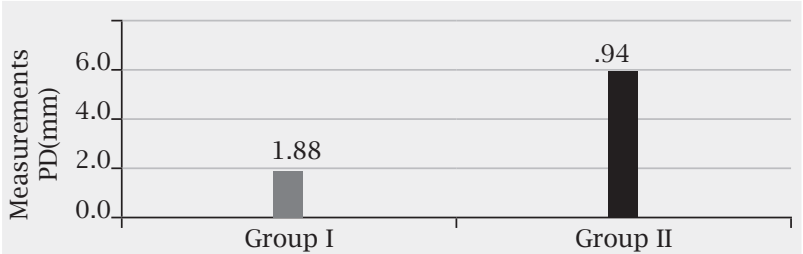

Graph 4: Comparison of PD between Group I and Group II

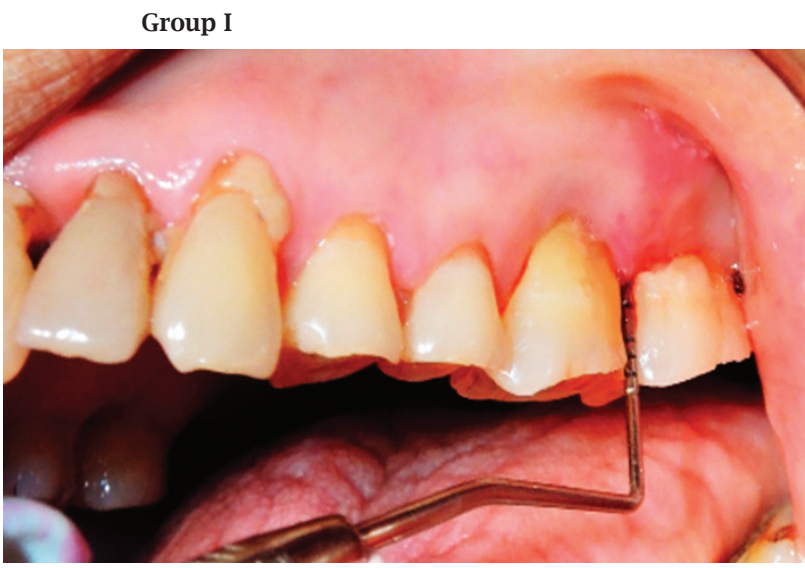

Figure 1: Probing pocket depth (PPD).

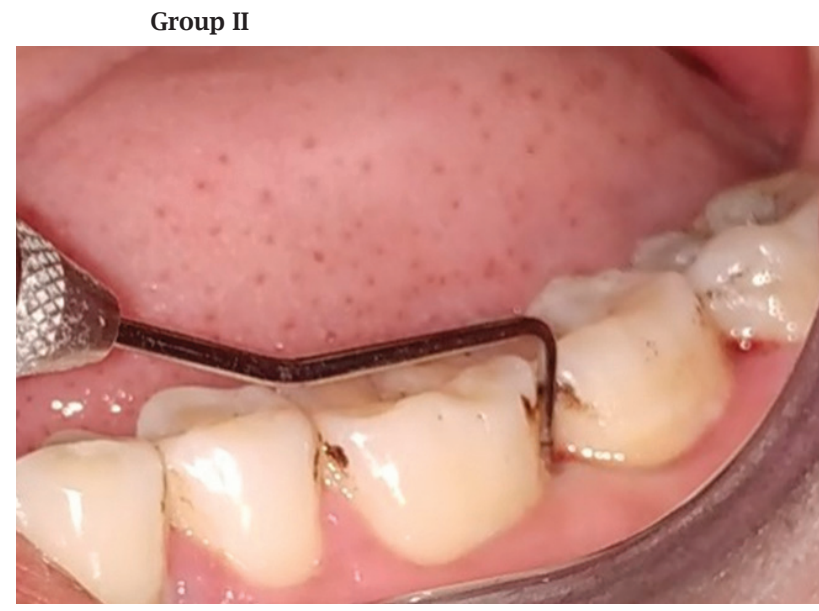

Figure 1: Probing pocket depth (PPD).

Group II respectively which was also nonsignificant. Table 1, Graph 3.

Mean score of PPD was $1.88 \pm 2.59$ for Group I and $5.94 \pm 2.56$ for Group II. There was a significant difference between the groups, which shows that deeper pockets $(p<0.001)$ were present in Group II as compared to Group I. Table 1, Graph 4

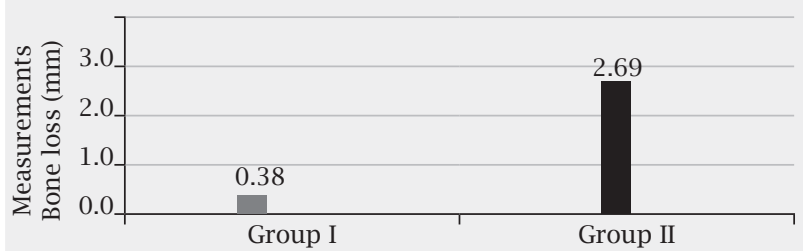

Graph 5: Comparison of bone loss between Group I and Group II

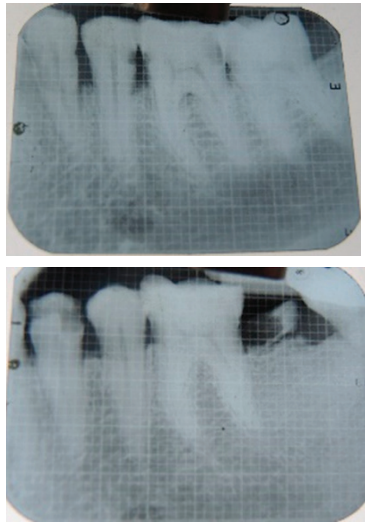

Figure 2: IOPA with grid.
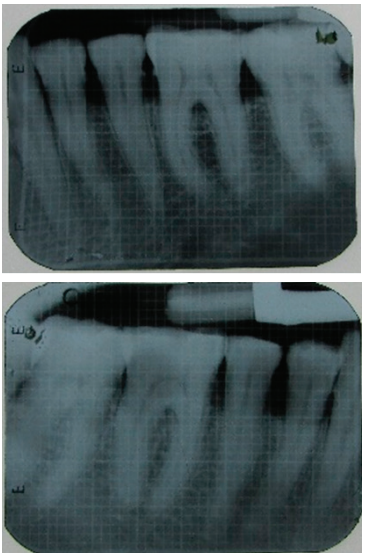

Figure 2: IOPA with grid.

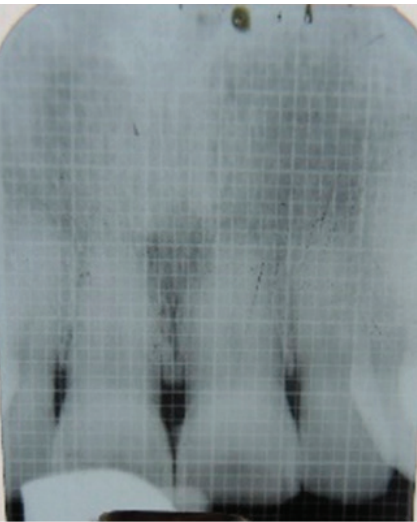

Figure 3: IOPA with grid.

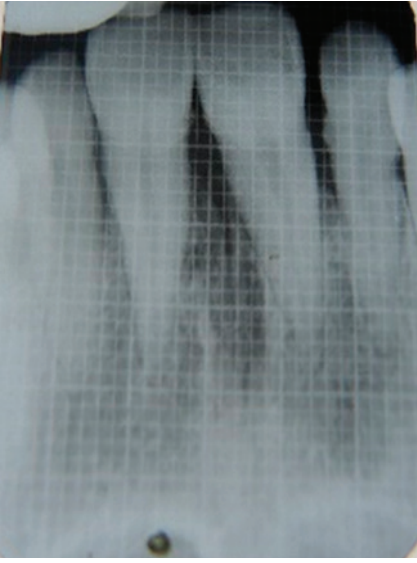

Figure 3: IOPA with grid.
Bone height was assessed using IOPA with grid. Mean value of bone loss was $0.38 \pm 1.13$ and $2.69 \pm 1.95$ for Group I and Group II respectively which shows statistically significant difference in bone height $(\mathrm{p}<0.00)$. There was reduced bone support was observed in Group II compared to Group I. Table 1, Graph 5

DISCUSSION 
During women's life cycle different hormonal changes occur at puberty, menstruation, pregnancy and menopause. Hormonal effects reflect physiological/pathological changes in almost all types of tissues of the body. These hormonal changes may show different clinical signs and symptoms on gingiva. Osteoporosis is a disease of bones that leads to an increased risk of fracture. In osteoporosis the bone mineral density (BMD) is reduced, bone microarchitecture deteriorates, and the amount and variety of proteins in bone is altered. The disease may be classified as primary type 1 and primary type $2 /$ secondary. Type 1 is associated with postmenopausal osteoporosis. Type 2 osteoporosis or senile osteoporosis occurs after age 75 and is seen in both females and males.

Menopause starts at the age of 45 to 55 which shows effect on bone which include reduced bone support, reduced bone mineral density and osteopenia and in severe cases osteoporosis is seen. Hence early diagnosis and preventive care may helpful in prevention of bone loss. Prevention of reduction in bone height may helpful in normal function and esthetics.

The mechanisms that could explain the relationship between periodontal disease and menopause are not fully understood. Some studies have shown a relationship between decreased bone mineral density and tooth $\operatorname{loss}^{21-23}$ and/or deterioration of certain periodontal parameters ${ }^{20,22,24}$ while others have failed to demonstrate such relationship. ${ }^{25,26}$

So, the present study was conducted to evaluate the effect of hormonal imbalances that occurs during menopause on periodontium.

For this study when intergroup comparison for plaque index was done it showed non-significant difference in PI ( $p>0.376)$ indicating that menopause don't have any direct correlation with plaque formation. These results were similar to study done by Alves et al. ${ }^{27}$

Gingival index also demonstrated non-significant difference ( $p>0.161$ ) which is similar to a study done by Alves et al. ${ }^{27}$

When DMFT index was compared there was significant difference ( $p>0.099)$ was found between two groups, in Group II number of missing teeth was more as compared to teeth that were decayed and restored which may be due to more bone loss in menopause. It was found by LaMonte et al that periodontal disease was responsible for $13 \%$ of teeth lost during a five-year follow-up period, although the mean number of teeth lost was quite small. ${ }^{28}$ So in present study subjects were diagnosed with generalised chronic periodontitis so it can not be justified that tooth loss that was found was due to effect of menopause or due to the existing periodontitis. These results were similar to the results that was found by Alves et al. ${ }^{27}$

However deeper pocket $(\mathrm{p}<0.001)$ and reduced bone support $(\mathrm{p}<0.00)$ was observed in Group II compared as to Group I.

It was also found that absence of estrogen and progesterone hormones in menopause contributes to changes in the periodontal tissues. ${ }^{29}$ In present study more deeper pockets were seen in Group II as compared to Group I that signifies that it was effect of menopause. Similar results with more deeper pockets was found by Alves et al in menopausal women compared to premenopausal women. ${ }^{27}$

In the present study radiographic evaluation was done to check the bone height, reduced bone support $(\mathrm{p}<0.00)$ was observed in Group II as compared to Group I. No any similar studies was done to evaluate the bone height, but Teitelbaum ${ }^{30}$ conducted study that showed decreased estrogen also results in reduced inhibition of osteoclastogenesis and more osteoclastic activity. ${ }^{30}$ So, it can be concluded that estrogen deficiency may leads to more osteoclastic activity which shows reduced bone height in postmenopausal women.

Hormonal imbalance during menopause may leads to reduce the bone height. So, subjects at premenopausal and menopausal stage may treated with care by gentle handling of soft tissue and subjects education and motivation for oral hygiene maintence and calcium rich diet. Along with that with expert opinion from a gynecologist subjects should have to undergo the hormonal replacement therapy (HRT) if needed and frequent recall visits to the periodontist for evaluation of periodontal health.

\section{CONCLUSION}

The findings of the present study suggest that postmenopausal women have more severe periodontal destruction as compared to premenopausal women. So, healthy diet and continuous periodontium monitoring is necessary at premenopausal and at menopausal condition and that subjects may need extra care for the same. 


\section{REFERENCES}

1. Joon Otomo - Corgel. Periodontal therapy in female patients. Carranza 10th edition: 636

2. Leblebicioglu B, Connors J, Mariotti A. Principles of endocrinology. J Periodontol 2000. 2013;6:54-68.

3. Monroe SE, Menon KM. Changes in reproductive hormone secretion during the climacteric and postmenopausal periods. Clin Obstet Gynecol. 1977;20:113-22.

4. Vitiello D, Naftolin F, Taylor HS. Menopause: Developing a rational treatment plan. Gynecol Endocrinol. 2007;23:682-91.

5. Friedlander AH. The physiology, medical management and oral implications of menopause. J Am Dent Assoc. 2002;133:73-81.

6. Forabosco A, Criscuolo M, Coukos G, Uccelli E, Weinstein R, Spinato S, Botticelli A, Volpe A. Efficacy of hormone replacement therapy in postmenopausal women with oral discomfort. Oral Surg Oral Med Oral Pathol 1992;73:570-4.

7. Yalcin F, Gurgan S, Gurgan T. The Effect of Menopause, Hormone Replacement Therapy (HRT), Alendronate (ALN), and Calcium Supplements on Saliva. J Contemp Dent Pract. 2005;2:10-7.

8. Becker C. Pathophysiology and clinical manifestations of osteoporosis. Clin Cornerstone. 2006;8:19-27.

9. Lerner UH. Bone Remodelling in Post-meno-pausal Osteoporosis. J Dent Res. 2007;85:584-95.

10. Wactawski-Wende J. Periodontal diseases and osteoporosis: association and mechanisms. Ann Periodontol. 2001;6:197-208.

11. Mariotti A. Estrogen and extracellular matrix influence human gingival fibroblast proliferation and protein production. J Periodontol. 2005;76:1391-7.

12. Shu L, Guan SM, Fu SM, Guo T, Cao M, Ding Y. Estrogen modulates cytokine expression in human periodontal ligament cells. J Dent Res. 2008;87:142-7.

13. Liang L, Yu JF, Wang Y, Ding Y. Estrogen Regulates Expression of Osteoprotegerin and RANKL in Human Periodontal Ligament Cells Through Estrogen Receptor Beta. J Periodontol. 2008;79:1745-51.

14. World Health Organization. WHO scientific group on the assessment of osteoporosis at primary health care level. In Summary meeting report. 2004;5:5-7.

15. Von Wowern N, Klausen B, Kollerup G. Osteoporosis: a risk factor in periodontal disease. J Periodontol. 1994;65:1134-8

16. Payne JB, Reinhardt RA, Nummikoski PV, Patil KD. Longitudinal alveolar bone loss in postmenopausal osteoporotic/osteopenic women. Osteoporosis International. 1999;10:34-40.

17. Mittermayer F, Enzelsberger H, Nouri K, Nell A. Reducing disability among the elderly in Europe. Lancet. 1998;31;351:375-6.

18. Turesky S, Gilmore ND, Glickman I. Reduced plaque formation by the chloromethyl analogue of victamine C. J Periodontol. 1970;4:41-3.

19. Löe H, Theilade E, Jensen SB. Experimental gingivitis in man. J Periodontol. 1965;36:177-8

20. Knutson JW, Klein H. Studies on dental caries: IV. Tooth mortality in elementary school children. Public Health Reports. 1938;24:102132.

21. Renvert S, Berglund J, Persson RE, Persson GR. Osteoporosis and periodontitis in older subjects participating in the Swedish National Survey on Aging and Care (SNAC-Blekinge). Acta Odontol Scand. 2011;69:201-7.

22. Nicopoulou-Karayianni K, Tzoutzoukos P, Mitsea A, Karayiannis A, Tsiklakis K, Jacobs R. Tooth loss and osteoporosis: the osteodent study. J Clin Periodontol. 2009;36:190-7.

23. Inagaki K, Kurosu Y, Yoshinari N, Noguchi T, Krall EA, Garcia RI. Efficacy of periodontal disease and tooth loss to screen for low bone mineral density in Japanese women. Calcif Tissue Int. 2005;77:9-14.

24. Ronderos M, Jacobs DR, Himes JH, Pihlstrom BL. Associations of periodontal disease with femoral bone mineral density and estrogen re-placement therapy: cross-sectional evaluation of US adults from NHANES III. J Clin Periodontol. 2000;27:778-86.

25. Famili P, Cauley J, Suzuki JB, Weyant R. Longitudinal study of periodontal disease and edentulism with rates of bone loss in older women. J Periodontol 2005;76:11-15.

26. Earnshaw SA, Keating N, Hosking DJ, Chilvers CE, Ravn P, McClung M, et al. Tooth counts do not predict bone mineral density in early postmenopausal Caucasian women. Int J Epidemiol. 1998;27:479-83.

27. Alves RC, Félix SA, Rodriguez-Archilla A, Oliveira P, Brito J, dos Santos JM. Relationship between menopause and periodontal disease: a cross-sectional study in a Portuguese population. Int J Clin Exp Med. 2015;8:11412-9.

28. 28. LaMonte MJ, Hovey KM, Genco RJ, Millen AE, Trevisan M, Wactawski-Wende J. Five-year changes in periodontal disease measures among postmenopausal females: the Buffalo OsteoPerio study. J Periodontol. 2013;84:572-84.

29. Mariotti A. Critical Reviews in Oral Bio and Med.1994,5:27-53.

30. Teitelbaum SL. Bone resorption by osteoclasts. Science. 2000:289:1504-8. 